Article

\title{
Business Model Innovation in Established SMEs: A Configurational Approach
}

\author{
Dorleta Ibarra $^{1, *}$, Ali Ziaee Bigdeli ${ }^{2} \mathbb{D}$, Juan Ignacio Igartua ${ }^{1}\left(\mathbb{D}\right.$ and Jaione Ganzarain ${ }^{1}$ \\ 1 Mechanical and Industrial Production Department, Faculty of Engineering, Mondragon University, \\ 20500 Mondragon, Spain; jigartua@mondragon.edu (J.I.I.); jganzarain@mondragon.edu (J.G.) \\ 2 The Advanced Services Group, Aston Business School, Aston University, Birmingham B4 7ET, UK; \\ a.bigdeli@aston.ac.uk \\ * Correspondence: dibarra@mondragon.edu
}

Received: 6 July 2020; Accepted: 8 August 2020; Published: 4 September 2020

\begin{abstract}
Small and medium-sized enterprises (SMEs) are at the heart of a nation's wealth creation, employment generation and economic development. To help SMEs stay competitive in a fast-changing environment, researchers have recently emphasized the relevance of business model innovation (BMI). However, BMI and its performance are not linear but rather a complex phenomenon that depends on contingency factors. Based on configurational theory, this study extends the BMI research to SMEs, exploring the management approaches and BMI capabilities that foster BMI in established SMEs. To achieve this objective, this study of a purposive sample of 78 Spanish SMEs adopts the fuzzy set qualitative comparative analysis (fsQCA) method. Results suggest three substantive conclusions. First, long-term managerial orientation is a key factor for the development of BMI in SMEs. Second, five BMI capabilities (sensing customer needs, sensing technological options, conceptualizing and experimenting, collaborating and BMI strategy) support, in combination with the management approach, the development of BMI in established SMEs. Third, open innovation (open flows of knowledge regarding market needs and the potential of technologies, as well as collaboration with customers) are concrete preconditions of business model innovation. Therefore, managers in SMEs need both to actively consider their management approach towards BMI, and to develop some key dynamic capabilities in their organizations to implement BMI, an approach also valid for post-Covid-19 management.
\end{abstract}

Keywords: business model innovation; dynamic capabilities; open innovation; post-Covid-19 management; managerial orientation; collaboration; configurational approach; fsQCA

\section{Introduction}

Small and medium-sized enterprises (SMEs) are an important part of a country's wealth creation, employment generation and economic development [1]. However, the fast-changing market environment is intensifying pressure on SMEs, leading to increasing interest from researchers and practitioners looking at business model innovation (BMI) through the lens of SMEs [2,3].

It is commonly accepted that business models represent the business logic of a company, describing how it creates, delivers and captures value [4], while BMI deals with the discovery of new and substantially different modes of value creation, value delivery and value capture in an existing business [5]. Thus, BMI allows firms to respond quickly to market opportunities, commercialize innovations through new business models, redefine existing markets or create new ones [6-8]. Consequently, the power of BMI as a source of superior market performance has been emphasized [9]. Moreover, if a company manages to avoid imitation by competitors, BMI provides a significant improvement in competitive advantage [10]. 
Despite the benefits and relevance of BMI for SMEs, our understanding of BMI and how to effectively conduct it is still limited [1]. Faced with the lack of a unified definition, Foss and Saebi [9], based on a broad review of extant literature, recently defined BMI as "designed, novel, non-trivial changes to the key elements of a firm's business model and/or the architecture linking these elements" (p. 17). This definition is built on certain assumptions. First, BMI requires novelty, and therefore it should address the search for value creation and value capture logics that are new to the firm and that result in observable changes for the stakeholders [3]. Second, BMI involves non-trivial changes, which means that it implies new ways of organizing business that go beyond the simple introduction of new products or improved processes [11,12]. Third, BMI needs to be designed and therefore demands actions from top managers and teams, who in turn require SMEs to hold both the relevant internal and external knowledge and the skills to sense and seize BMI opportunities [13-15].

In view of the above, BMI is usually presented as a complex phenomenon, since it implies complicated investment decisions, acquisition of resources and competences, organizational commitment and dealing with possible conflicts between the new and old business models $[16,17]$. Moreover, companies need to be able to profit from the new business model while protecting it from competitors [4].

Although facing this complexity is a challenge for companies of all sizes, the challenge can be compounded for SMEs [18]. Unlike larger firms, SMEs generally have fewer financial resources and limited time, smaller or non-existent R\&D facilities, fewer technical capabilities, difficulties in recruiting multidisciplinary skilled employees and less structured approaches to innovation $[19,20]$. Although these limitations present a challenge to innovating, if SMEs find ways to develop innovation capabilities, they can compensate for these difficulties by relying on the strengths associated with their size, such as a climate more receptive to change, procedures that are less bureaucratic, more flexible structures and adaptability [21-23]. In this context, authors are calling for further studies exploring the impact of SMEs' capabilities (everyday practices) on BMI, to understand how these companies work with BMI and its outcomes [9].

Additionally, some authors argue that SME-specific features can facilitate some innovation capabilities while hindering others [20]. In this context, an SME's management approach plays a key role. SMEs usually have flatter hierarchies which facilitate intra-firm communication, learning and sharing of mental models among a firm's members [24]. Conversely, SME behavior and culture is usually dominated by subjective approaches (i.e., personal beliefs, feelings, experiences or common sense) affecting critical decision processes such as the prioritization of innovation projects [25]. In line with this, SMEs generally managers, leaders and owners generally have overlapping domains [26]. This accelerates the decision-making process, which, in turn, tends to be dominated by leadership personalities [25]. Thus, SMEs' critical decision processes such as the prioritization of innovation projects become less rational and largely depend on a manager's intuition [27]. Consequently, further research into the relationship between SME management approaches and BMI capabilities should be developed.

In this sense, several frameworks, research models and empirical studies have been found suggesting different antecedents and outcomes to BMI [14,15,28,29]. However, the literature is widely diverse and the studies linking BMI with its antecedents and outcomes providing a comprehensive view of the phenomenon are limited $[1,9,13]$. Moreover, recent studies argue that the relationship between those drivers and BMI is not linear but rather is a complex phenomenon that depends on contingency factors $[9,30]$. These contributions adopt a configurational view, considered beneficial for management research [31], providing a more holistic approach that suggests that BMI is achieved through configurations combining different capabilities, practices, strategic resources or contextual conditions, rather than through any of these attributes in isolation [2,3,32-35].

Hence, this study addresses this gap in studying the influence of SME management approaches and BMI capabilities (BMICs) on BMI in established SMEs. To this end, we developed a framework based on a literature review of BMI in SMEs. We then performed a fuzzy-set qualitative comparative 
analysis (fsQCA) to find fine-grained insights into which conditions or combinations of conditions lead to BMI. Thus, the study contributes to research on BMI from different perspectives.

Firstly, we contribute to analyzing the BMI phenomena in established firms, a substantially different context compared to newly created companies [36]. Secondly, we contribute to the literature on management and dynamic capabilities, focusing on the management approach and five BMI capabilities, studying their role in BMI. Thirdly, the study increases our understanding of the antecedents to BMI in SMEs and of the range of different configurations an SME can adopt to implement it. Finally, the study provides some suggestions to SMEs managers on possible configurations for the adoption of BMI.

This empirical study is based on a self-administered questionnaire directed to the managers of a purposive sample of 78 Spanish SMEs. A configurational comparative method, namely fsQCA [37] is used, which by its hybrid nature provides a bridge between qualitative (case-oriented) and quantitative (variable-oriented) research, serving as practical approach for understanding complex, real-world situations [38,39]. FsQCA addresses cases as constellations of interconnected elements while highlighting that causality is complex [40]. Thus, it allows the researcher to determine which condition or configurations of conditions are necessary or sufficient for a given outcome to occur, providing causal recipes explaining a phenomenon [41]. This approach is increasingly supported by BMI researchers who suggest that fsQCA allows capturing the complexity of BMI [30].

The present paper is structured as follows. After this introduction, a review of the literature on BMI in SMEs is presented, bringing in key managerial approaches and presenting the dynamic capabilities related to BMI in SMEs. Then, the research framework and hypothesis are presented, the research method is explained, as is the fsQCA procedure, and the results are generated. The following section discusses the research results and hypothesis validation. Finally, the study's main conclusions, implications and limitations are addressed, and suggestions for future research are offered.

\section{Literature Review}

In the last decade, the BMI phenomenon has received increasing attention from both academics and practitioners. BMI is a rich concept which can be researched in several ways [5,42]. A huge number of definitions, approaches and theoretical underpinnings can be found related to BMI [9,42-45]. BMI can be considered a construct with a dual nature that brings together two concepts-namely, business models and innovation [36,46]. On the one hand, BMI is an evolutionary construct framed by business model research itself [47]. On the other hand, innovation is considered a complex phenomenon that can be defined in multiple ways [48]. Consequently, BMI is open to different interpretations. Thus, to study BMI in SMEs from a configurational approach, we consider several drivers taken from the BMI literature to develop our research framework and our research questions and propositions.

\subsection{BMI in Established Firms}

Scholars have considered the business model static for long time [44]. However, the strategy-oriented perspective on business models has fostered a dynamic view of the concept [5]. This has led to a new role for the business model as a means of addressing change and innovation in a company [49]. In this regard, business models are not static but rather in a continuous state of change in terms of components, relationships and structure [42,49].

Within this dynamic view of business models, multiple approaches have been used to refer to changes in a business model. One of the first explicit references to BMI is found in Mitchell and Coles's [50] work titled "The ultimate competitive advantage of continuing business model innovation". The authors discuss how managers from established firms can purposively innovate their business model, through replacements and improvements, to achieve a sustainable competitive advantage and outperform their competitors.

Since the publication of that article, a growing number of studies have focused on the innovation dimension of the business model [9]. In this context, it is considered that for changes in an existing business model to be considered BMI, they must be purposeful changes driven by a managerial 
action $[9,10,51,52]$. This implies that an established firm has become involved in a BMI process and, as a result, has deliberately changed its existing business model.

\subsection{SME Management Approach}

In the context of SMEs, the role of managers is especially relevant, since ownership and management are typically concentrated in the same individual, who is the one who makes the decisions [53,54]. Therefore, various works focusing on managers' and teams' cognitions and BMI argue that managers' actions are affected by their past strategic choices [54], especially when those choices led to success. Arbussà et al. [20] suggest that SME CEOs are more likely to exhibit resistance to change, as their fear of loss is stronger than the attraction of potential gain, a dynamic which can hinder BMI.

In this vein, some authors suggest that innovation activities in SMEs are mainly driven by the manager's vision [55]. Consequently, SME behavior and culture is usually dominated by subjective approaches (i.e., personal beliefs, feelings, experiences or common sense) that affect critical decision processes such as the prioritization of innovation projects [25].

For an SME to innovate, it must have an organizational culture that fosters values, beliefs and behaviors that encourage innovation [56]. Previous research indicates that culture influences BMI [57]. Moreover, an organizational culture that promotes innovation and creativity will encourage an SME's members to take risks, develop new ideas and sense new opportunities [58]. This in turn can stimulate BMI.

In addition, researchers have observed that in the course of successive economic crises, managers have developed a conservative style aimed at reducing costs to the detriment of both R\&D and capital investment, subsequently resulting in poorer growth rates [59]. Furthermore, according to a survey conducted by McKinsey, over the last few years companies have adopted a short-term performance logic, leading to the destruction of long-term value and affecting the competitiveness and survival of the firms [60].

\subsection{Business Model Innovation Capabilities (BMICs)}

Among internal factors enabling BMI, the dynamic capabilities theory is gaining attention in the literature $[2,15,61]$. Furthermore, some scholars have found that firms follow different paths towards BMI that may require different dynamic capabilities [32,62]. It is also suggested that SMEs with higher levels of dynamic capabilities achieve higher levels of BMI than SMEs with lower dynamic capabilities [32,61].

Therefore, SMEs need to develop strong innovation capabilities that will allow them to sense and seize opportunities and transform their business models to exploit these opportunities [15]. From among the various methods for approximating a firm's capabilities and BMI [62,63], for this study we adopted the approach of Janssen et al. [64], as to our knowledge this is one of the methods that comes closest to quantitatively measuring innovation capabilities in BMI [65]. Furthermore, Kiani et al. [66] recently showed the positive relationship of these capabilities on BMI. Thus, we further adapted these BMICs to an SME context, defining them as (1) sensing customer needs, (2) sensing technological options, (3) conceptualizing and experimenting, (4) collaborating and (5) BMI strategy.

Sensing customer needs: An initial step towards enabling BMI is an understanding and monitoring of the ecosystem that surrounds the firm [12,15]. Various authors argue that identifying emerging market demands and sensing customers with unmet needs are essential for BMI [15]. Moreover, Arbussà et al. [20] found that strategic sensitivity—that is "being able to anticipate the future needs of the customers and users of the product or service"-is less natural and consequently more critical for SMEs.

Sensing technological options: Firms that are able both to gain knowledge of new and emerging technologies [14] and to recognize alternative business models among competitors are more likely to identify new business model opportunities [67]. Furthermore, sensing technological options may become a critical capability in the current context, where digital transformation is gaining attention 
with regard to BMI [68]. Firms must be up to date with new technological developments to identify threats and opportunities and to exploit them through new value propositions and business models, thereby enabling the firms to create value for customers and capture the value back [7,69].

Conceptualizing and experimenting: Some authors suggest that SMEs tend to focus on particular components, such as value propositions, target customers or the internal value chain, when conducting BMI $[20,70]$. BMI in turn requires the systematic iterative deployment of new knowledge related to technological development, the market and new business model conceptualizations $[14,62]$. Thus, an experimental capability that supports action and commitment to BMI is required in SMEs [71]. Furthermore, new business models are difficult to conceptualize, because of both the dominant logic of the company [12] and their intangible nature [65]. As a result, companies need to think outside of the box, experiment with new concepts of business models, generate new ideas and transform these rough ideas into viable value propositions that should be understandable and valuable to both internal and external actors $[14,62,65]$. In addition, Bouwman et al. [3] recently found a positive relationship between resources for business model experimentation and BMI in the context of SMEs.

Collaborating: BMI may require new collaborative approaches to co-design and co-produce new value propositions or new governance capabilities [15,71]. This is even more relevant in the case of SMEs, which, lacking resources and technical capabilities, will need external help, such as new technological partners or research and knowledge collaborations [54,72]. In this vein, various scholars have found that open innovation positively influences BMI in SMEs [34,54,73]. Furthermore, research suggests that SMEs tend to develop inbound open innovation activities: that is, accessing resources, knowledge and innovation ideas from the outside to complement their in-house resource base. Inbound activities involve exploratory learning with different external partners related to distinct knowledge sources [74,75]. In this context, collaboration with universities or research institutes for research and development [73] or acquiring resources from the outside [34] is stressed as critical for BMI in SMEs.

BMI strategy: Finally, scaling up can be the most critical step for BMI, as it may meet significant internal resistance $[15,76,77]$. When disseminating a new business model, conflicts between established and new business models need to be managed [78]. In addition, SMEs must be able to change their business model while at the same time building and maintaining sustainable performance [49]. A clear BMI strategy facilitating the diffusion of new business model concepts that are aligned with the company's growth strategy is therefore required to build new competencies and implement organizational renewal, both of which are fundamental to the ongoing BMI [14,61].

\subsection{BMI Drivers in SMEs: A Configurational Approach}

Recent studies argue that the relationship between drivers and BMI is not linear phenomenon but rather a complex one that depends on contingency factors $[9,79]$. Therefore, some authors address such complexity through a configurational approach, whereby the effects of certain drivers produce equifinal consequences [33].

Prior research that has explored the capabilities SMEs should develop to achieve BMI has followed both dynamic capabilities and configurational approaches [2,32]. From these findings, it can be concluded that SMEs follow different configurational paths towards BMI, and that some capabilities that might drive BMI in one firm will not necessarily prove successful for BMI in another firm.

\section{Theoretical Framework}

\subsection{Research Framework}

To explore the management approaches and BMI capabilities that foster BMI in established SMEs, this paper provides a configurational analysis for studying the core factors of BMI.

We have developed a research model rooted in dynamic capabilities theory [80] and configurational theory [81] that support both the influence of managers on BMI $[20,53,54]$ and the critical capabilities 
related to BMI $[14,28,32,62]$. The dynamic capabilities theory was first introduced by Teece, Pisano and Shuen [81], who defined the dynamic capabilities as "the firm's ability to integrate, build and reconfigure internal and external competences to address rapidly changing environments (p. 516)". Configurational theory views organizations as constellations of interconnected elements and states that the whole is best understood from a systemic perspective [80]. Configurational theory aims therefore to capture patterns among environmental, strategic and organizational attributes that can lead to organizational effectiveness, but also stresses that causality is complex [40].

We mainly focused on the management approach and on the dynamic capabilities of the firm. Specifically, the management approach refers to the long-term managerial orientation [82] and the managerial promotion of an innovative culture in the firm [57] as drivers of BMI. In complementary fashion, the paper refers to five specific dynamic capabilities for BMI [66]: (1) sensing customer needs, (2) sensing technological options, (3) conceptualizing and experimenting, (4) collaborating and (5) BMI strategy.

Therefore, we aimed to explore which drivers can be more effective in promoting BMI in the context of established SMEs. Based on the two theoretical perspectives mentioned above, this paper explores possible configurations for BMI along two dimensions (management approach and BMI capabilities). The framework of this paper is diagrammed in Figure 1. We bridged the gap by testing the synergistic effects of the management approach and dynamic capabilities to explore how managers and firms face BMI. The approach to this problem can also help managers better integrate dynamic capabilities to achieve BMI in their companies. The originality of the proposed research model is based on the integration of both configurational theory and dynamic capabilities theory, and therefore in the assumption than more than one path exists for BMI in SMEs.

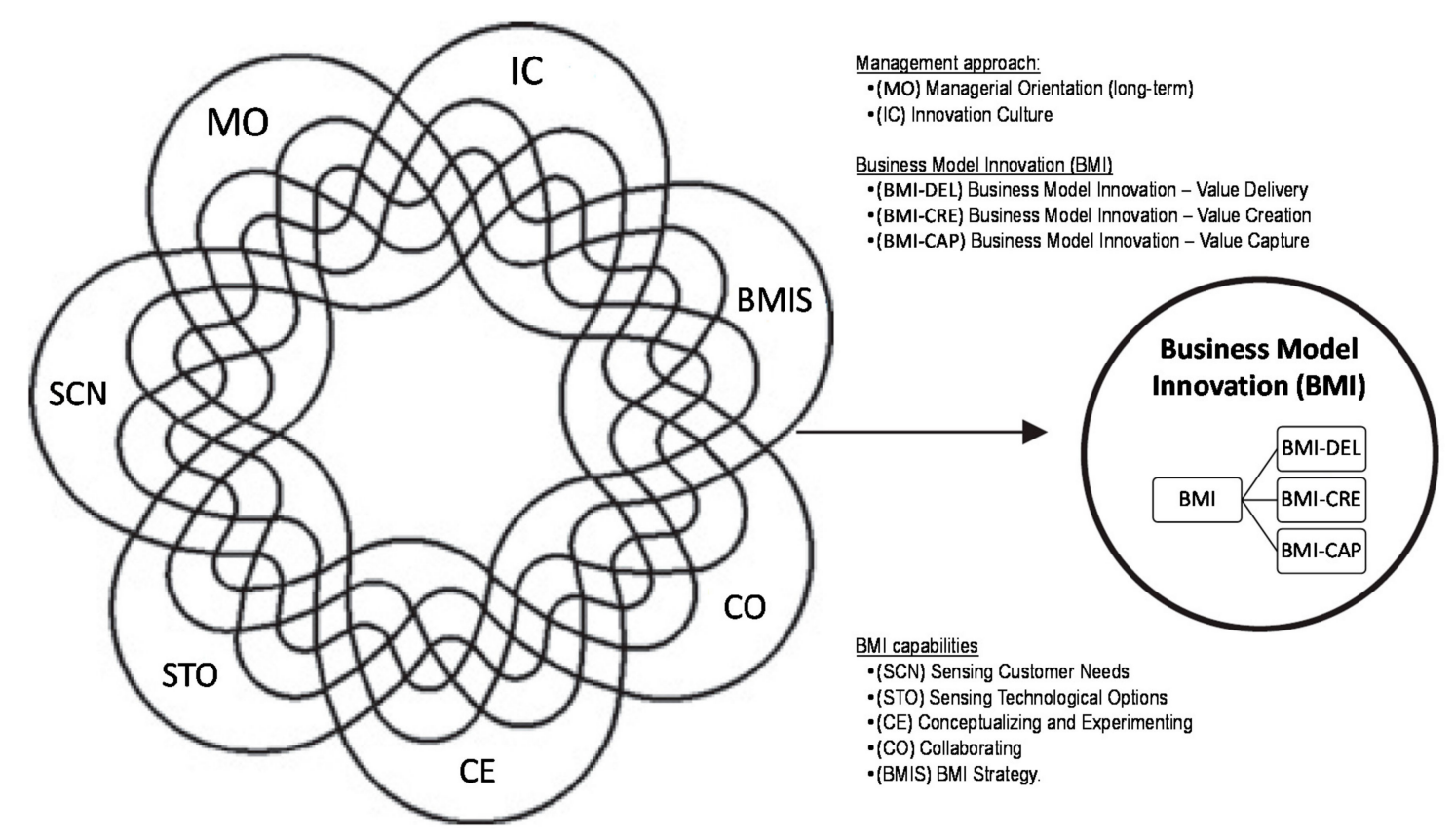

Figure 1. Research model.

According to the configurational approach, three main assumptions support the explanation of complex phenomena such as BMI. Firstly, it is assumed that more than one path exists to the same outcome (equifinality). Secondly, an outcome rarely has a single cause and can result from the different combinations of conditions (conjunction). Thirdly, causally related conditions in one configuration may not be related in another (asymmetry) [80]. Based on this, it is assumed that SMEs can follow many paths to BMI that can be equally effective [3]. 
Furthermore, building on the dynamic capabilities view, we suggest that those effective paths would reflect the underlying managerial approach and dynamic capabilities of the firm, which are heterogeneous and vary across firms [83].

Additionally, SMEs do not necessarily have to be strong in all dynamic capabilities, as these are multi-faceted [15]. These thoughts are supported by prior research that shows how SMEs follow different paths to BMI that combine capabilities and practices [2,3,32]. Bearing all this in mind, we developed the following research proposition:

Research proposition: SMEs can achieve BMI through different, equally effective, combinations of managerial orientation, innovation culture and BMI capabilities (sensing customer needs, sensing technological options, conceptualizing and experimenting, collaborating and developing a BMI strategy).

\subsection{Fuzzy-Set Qualitative Comparative Analysis (fsQCA)}

This work adopted an fsQCA approach to identify the core drivers of BMI in established SMEs. FsQCA reveals multiple pathways to BMI and therefore exposes the key antecedents that provide preconditions for BMI in established firms $[84,85]$.

FsQCA is fundamentally different from the traditional statistical method. Whereas regression analysis focuses on the analysis of factor interaction, fsQCA is outcome-oriented [86-88]. FsQCA is a set-theoretic method used to investigate complex causal configurations. Although it is also commonly used with quantitative data, it was originally developed for qualitative case-oriented studies [41]. Through a systematic cross-case analysis, fsQCA finds the conditions, or configurations of conditions, that are necessary or sufficient for an outcome of interest to occur [89]. Thus, it helps to find configurational paths leading to an outcome.

\subsection{Sample and Procedure}

We developed a self-administered online questionnaire to collect data. Most of the variables were taken from previously validated multi-item scales and were adapted slightly to fit the BMI context. Items were translated from English to Spanish following the back-translation method to ensure equality of the items [90].

Reliability and validity of all variables and items were tested by four academicians, based on their feedback some scales were modified. Thereafter, a pilot test emulating the procedure to be used for the final sample was conducted with eight potential respondents who were not included in the final sample. The link to the survey questionnaire was shared with participants and, after we obtained the responses, we conducted personal interviews with them in which we asked about the clarity of the instrument while checking that the terminology was understandable [91]. Content validity was established by rewording and simplifying several items based on the feedback received. Reliability and validity of the measurement instrument was tested through partial least squares structural equation modeling (PLS-SEM).

The sample comprises 267 SMEs from a wide range of industries located in the Basque region (Spain), selected from the regional government's database. These SMEs had participated in government funding programs in the last three years related to (1) improving competitiveness and (2) business transformation through differentiation, diversification and the contribution of value to products, services and business models.

The survey invitation was sent via email to CEOs between May and June 2019. During this period, two reminders were sent every other week to ensure enough responses. The data collected was cleaned of missing values, suspicious patterns and outliers [92]. The final sample comprised 78 cases (final valid responses $=29.21 \%$ ).

Most survey respondents were top-level managers (82.1\%). Responses were collected from manufacturing (59\%), industrial services (18\%), ancillary services $(7.7 \%)$ and ICT $(10.3 \%)$ industries. Companies were categorized according to EU commission recommendations [93]. The sample 
predominantly comprised small firms $(70.5 \%)$ followed by medium-sized firms $(25.6 \%)$ and micro firms $(3.8 \%)$.

We analyzed potential biases between early and late respondents, performing t-test comparisons between group means for all constructs [94]. No significant differences were found. Moreover, since we relied on single respondents, common method variance was tested using Harman's single-factor test [95]. The main factor showed only $14.30 \%$ of the total variance, which indicates that common method variance was not a problem in this study.

\subsection{Definition and Validation of the Measurement Instrument}

To develop the measurement instrument, a comprehensive list of validated measures was gathered and generated based on a review of business models, BMI, dynamic capabilities and management approaches. Constructs were based on items that were introduced in the questionnaire.

With regard to BMI capabilities, items that composed sensing customer needs and sensing technological options were measured using three item-scales adopted from Janssen et al. [64]. Three items measured collaborating capability based on Van de Vrande et al. [96]. The fourth capability, BMI strategy, was measured with a four-item scale adapted from Huurinainen [97]. For the fifth BMI capability (conceptualizing and experimenting), a new six-item scale was developed based on Janssen et al. [64], Mezger [14] and Frankenberger et al. [12].

As for the variables related to the management approach, innovative culture was measured with a five-item scale from the study by Hock et al. [57]. Managerial orientation was measured based on a three-item scale from Covin and Slevin [98].

BMI was measured by assessing the changes introduced in the three dimensions comprising business models (value delivery, value creation and value capture) as established in the literature $[4,5]$. Value delivery and value creation were measured with six-item and four-item scales, respectively, that were based on Zott and Amit [99] and Schrauder et al. [100]. Value capture, in turn, was based on a four-item scale from Verhagen [101].

A 5-point Likert scale was used to measure all the variables. Following Sarstedt et al. [102] recommendations, all the antecedent conditions (BMI capabilities, innovative culture and managerial orientation) were developed as reflective latent variables, while BMI, due to its multidimensional nature reflected by its three dimensions, was operationalized as type I reflective-reflective higher-order constructs (HOCs).

The validation of the measurement model was developed in two steps. Firstly, items were evaluated using exploratory factor analysis (EFA). Two different EFAs were developed, one to explore the antecedent conditions and another one to analyse the outcome (i.e., BMI). Secondly, a confirmation of dimensionality was performed using Smart-PLS 3 software [103], since various authors suggest it as an appropriate approach for assessing measurement models [104,105].

To develop the EFA for antecedent conditions, a principal component analysis based on the PROMAX oblique rotation method was developed, assuming the correlations between the components based on BMI literature [104,106]. A highly significant X2-value for the Bartlett's test of sphericity and a Kaiser-Meyer Olkin value of 0.82 indicated that the data was suitable for calculating an EFA. All indicators revealed high communalities, with values between 0.54 and $0.89[107,108]$. Based on BMI theory reasoning, an EFA was applied, restricting the solution to seven factors. The solution explained $76.33 \%$ of the total variance (Table 1). Subsequently, the corrected item-to-total correlations and the Cronbach's alpha values were calculated to assess the reliability of the solution. Values related to item-to-total correlations ranged between 0.38 and 0.82 , with the values of three items below the threshold of 0.5 [109]. However, based on theory, these items were kept for confirmatory analysis. By contrast, Cronbach's alpha values fluctuated between 0.695 and 0.938 ; only one did not exceed the recommended 0.70 cut-off value [110]. 
Table 1. Exploratory factor analysis for antecedents.

\begin{tabular}{|c|c|c|c|c|c|c|c|}
\hline Item & Factor 1 & Factor 2 & Factor 3 & Factor 4 & Factor 5 & Factor 6 & Factor 7 \\
\hline MO1 & 0.49 & & & & & & \\
\hline MO2 & 0.89 & & & & & & \\
\hline MO3 & 0.75 & & & & & & \\
\hline IC1 & & 0.74 & & & & & \\
\hline IC2 & & 0.89 & & & & & \\
\hline IC3 & & 0.85 & & & & & \\
\hline IC4 & & 0.87 & & & & & \\
\hline IC5 & & 0.94 & & & & & \\
\hline SCN1 & & & 0.69 & & & & \\
\hline SCN2 & & & 0.91 & & & & \\
\hline SCN3 & & & 0.75 & & & & \\
\hline STO1 & & & & 0.94 & & & \\
\hline STO2 & & & & 0.65 & & & \\
\hline STO3 & & & & & & & 0.45 \\
\hline CE1 & & & & & 0.84 & & \\
\hline CE2 & & & & & 0.85 & & \\
\hline CE3 & & & & & 0.58 & & \\
\hline CE4 & & & & & 0.84 & & \\
\hline CE5 & & & & & 0.87 & & \\
\hline CE6 & & & & & 0.78 & & \\
\hline $\mathrm{CO} 1$ & & & & & 0.41 & & \\
\hline $\mathrm{CO} 2$ & & & & & & 0.79 & \\
\hline $\mathrm{CO} 3$ & & & & & & 0.86 & \\
\hline BMIS1 & & & & & & & 0.96 \\
\hline BMIS2 & & & & & & & 0.88 \\
\hline BMIS3 & & & & & & & 0.85 \\
\hline BMIS4 & & & & & & & 0.83 \\
\hline
\end{tabular}

Principle component analysis with PROMAX rotation. MO: managerial orientation; IC: innovation culture; SCN: sensing customer needs; STO: sensing technological options; CE: conceptualizing and experimenting; BMIS: BMI strategy.

The second EFA measured the accuracy of BMI following standard procedures for HOCs [111]. Thus, a principal axis factoring analysis with an oblique rotation method (PROMAX) was developed. A highly significant X2-value for the Bartlett's test of sphericity and a Kaiser-Meyer Olkin value of 0.86 showed that the data was adequate for conducting an EFA. All indicators revealed high communalities, with values between 0.34 and 0.83 , being the lower value close to the cut-off of 0.4 , thus, items were considered to be well represented [108]. Based on theory reasoning, the EFA was conducted restricting the solution to three factors. The solution explained $67.12 \%$ of the total variance (Table 2). One item related to value delivery was eliminated, since it was below the threshold of 0.5 [109]. Subsequently, the corrected item-to-total correlations and the Cronbach's alpha values were calculated to assess the reliability of the solution. Values related to item-to-total correlations ranged between 0.54 and 0.79 , well above the threshold of 0.5 [109]. On the other hand, Cronbach's alpha values were 0.85 for value delivery, 0.87 for value creation and 0.80 for value capture, exceeding the 0.70 cut-off value recommended by Nunally [110]. 
Table 2. Exploratory factor analysis for BMI.

\begin{tabular}{lccc}
\hline Item & Factor 1 & Factor 2 & Factor 3 \\
\hline BMI-DEL 1 & 0.79 & & \\
BMI-DEL 2 & 0.75 & & \\
BMI-DEL 3 & 0.69 & & \\
BMI-DEL 4 & 0.46 & & \\
BMI-DEL 5 & & & \\
BMI-DEL 6 & 0.60 & 0.67 & \\
BMI-CRE 1 & & 0.80 & \\
BMI-CRE 2 & & 0.52 & \\
BMI-CRE 3 & & 0.75 & 0.61 \\
BMI-CRE 4 & & & 0.63 \\
BMI-CAP 1 & & & 0.93 \\
BMI-CAP 2 & & & \\
BMI-CAP 3 & & & \\
BMI-CAP 4 & & & \\
\hline
\end{tabular}

Principal axis factoring with PROMAX rotation. BMI-DEL: Value delivery dimension; BMI-CRE: value creation dimension; BMI-CAP: value capture dimension.

After the EFA, a confirmation of dimensionality was performed using PLS-SEM. A nonparametric bootstrapping with 5000 replications without sign changes was applied to obtain the standard errors for all estimations in the measurement models [112]. Indicator reliability (Appendix A), composite reliability $(\mathrm{CR})$ and discriminant validity were tested to evaluate the reliability and validity of the scale. All items for antecedent conditions revealed highly significant $(t>4.20)$ with factor loadings in the range of 0.64 and 0.94 , above the recommended cut-off value of 0.4 for indicator reliability [112]. Internal consistency reliability was supported, as CR values ranged from 0.83 to 0.96 , exceeding the minimum threshold of 0.7 [113]. Average variance extraction (AVE) reached values between $62 \%$ and $84 \%$, above $50 \%$, thereby confirming convergent validity [114]. The Fornell-Larcker criterion was met, since the square roots of the AVEs for all constructs were greater than the construct's strongest correlation with other constructs. Furthermore, the heterotrait-monotrait ratio of correlations (HTMT) ratios ranged from 0.17 to 0.80 , lower than the threshold of 0.85 , suggesting that the constructs were empirically distinct [115].

To assess the reliability and validity of the BMI constructs as type I reflective-reflective HOCs, we first calculated the indicator reliability (Appendix B), CR and discriminant validity of the three low-order constructs. All items were highly significant $(t>4.20)$, with factor loadings in the range of 0.67 to 0.89 , above the recommended cut-off value of 0.4 for indicator reliability [112]. Internal consistency reliability was supported, as $C R$ values ranged from 0.87 to 0.91 , exceeding the minimum threshold of 0.7 [113]. AVEs reached values between $63 \%$ and $72 \%$, above 50\% [114]. The Fornell-Larcker criterion was met (all variables were lower than their highest squared inter-construct correlation). The HTMT values for all first-order constructs ranged from 0.17 to 0.80 and were therefore below the conservative threshold of 0.85 [115].

Once the three low-order constructs were validated (BMI-DEL, BMI-CRE and BMI-CAP), the reliability and validity of the BMI HOC was tested using the same assessment method. Indicator reliability (Annex B), CR, and discriminant validity were also calculated to test the reliability and validity of the scale. All indicators were highly significant $(t>4.20)$, with factor loadings in the range of 0.75 to 0.90, above the recommended cut-off value of 0.4 for indicator reliability [112]. Internal consistency reliability was supported, as CR value was 0.89 , exceeding the threshold of 0.7 [113]. AVE reached a value of $72 \%$, above $50 \%$, thereby confirming convergent validity [114]. Discriminant validity based on the Fornell-Larcker criterion was met (all variables were lower than their highest squared inter-construct correlation). 


\section{Research Method and Results}

Based on the research framework (see Figure 1) and the propositions posited, fsQCA was performed to obtain fine-grained results regarding the relationship between managerial orientation, innovative culture and BMICs leading to BMI. To conduct the analysis standards of good practice on the use of QCA [41,116], a method that provides assurance on how to perform fsQCA in a technically correct manner and in a complete way, was followed.

The fsQCA process includes (1) the calibration of raw data into fuzzy membership scores, (2) the analysis of necessary conditions, (3) the organization of cases into logically possible combinations through a truth table, (4) the analysis of sufficiency due to the logical minimization process of the truth table and (5) the interpretation of the resultant configurational paths [116].

\subsection{Calibration}

Following the aforementioned steps, the original 5-point Likert scale was first translated into fuzzy-set scores. We calculated the average scores of multi-item measures to obtain each latent variable value [117]. We then applied the direct calibration method [37] specifying three anchors, one for full membership (value $=0.95$ ), one for the crossover point (value $=0.50$ ) and one for full non-membership (value $=0.05$ ) based on the percentiles (75th, 50th and 25th) of our sample data [118]. Table 3 presents the descriptive statistics of the conditions and outcome, together with the calibration values. To avoid cases with exact values of 0.5 , we added 0.001 to these scores to be able to include them in the analysis [84].

Table 3. FsQCA: Descriptive statistics of the conditions and outcome.

\begin{tabular}{|c|c|c|c|c|c|c|c|c|c|}
\hline \multirow{2}{*}{ Statistics } & \multirow{2}{*}{ Variables } & \multirow{2}{*}{ Coding } & \multicolumn{4}{|c|}{ Descriptive Statistics } & \multicolumn{3}{|c|}{ Calibration Criteria } \\
\hline & & & Mean & Std. Dev. & Min & Max & $75 \%$ & $50 \%$ & $25 \%$ \\
\hline \multirow{7}{*}{ Conditions } & Managerial orientation & $\mathrm{MO}$ & 3.44 & 0.91 & 1.00 & 5.00 & 4.00 & 3.67 & 2.75 \\
\hline & Innovative culture & IC & 3.95 & 0.76 & 1.80 & 5.00 & 4.60 & 4.00 & 3.60 \\
\hline & BMI strategy & BMIS & 3.48 & 0.81 & 1.00 & 5.00 & 4.00 & 3.75 & 3.00 \\
\hline & Sensing customer needs & $\mathrm{SCN}$ & 3.63 & 0.62 & 1.67 & 5.00 & 4.00 & 3.67 & 3.33 \\
\hline & Sensing technological options & STO & 3.61 & 0.59 & 2.00 & 5.00 & 4.00 & 3.67 & 3.33 \\
\hline & Conceptualizing and experimenting & $\mathrm{CE}$ & 3.22 & 0.74 & 1.80 & 5.00 & 3.80 & 3.40 & 2.60 \\
\hline & Collaborating & $\mathrm{CO}$ & 3.45 & 0.78 & 1.67 & 5.00 & 4.00 & 3.67 & 3.00 \\
\hline Outcome & BMI & BMI & 3.21 & 0.68 & 1.00 & 4.92 & 3.67 & 3.27 & 2.85 \\
\hline
\end{tabular}

\subsection{Analysis of Necessary and Sufficient Conditions}

Once the data had been calibrated, the assessment of necessity was carried out. The existence of necessary conditions implies that if the condition is present or absent, then the outcome is also present or absent [41]. A condition is considered necessary if it exceeds the consistency threshold of 0.9 [116]. Table 4 shows that no single condition or its negation was necessary for the outcome to occur, as the highest consistency value was 0.745 for sensing technological options.

Table 4. FsQCA: Necessary and sufficient conditions.

\begin{tabular}{cccccc}
\hline $\begin{array}{c}\text { Conditions } \\
\text { Tested }\end{array}$ & Consistency & Coverage & $\begin{array}{c}\text { Conditions } \\
\text { Tested }\end{array}$ & Consistency & Coverage \\
\hline MO & 0.604 & 0.606 & $\sim$ MO & 0.500 & 0.487 \\
IC & 0.624 & 0.655 & $\sim$ IC & 0.475 & 0.443 \\
BMIS & 0.703 & 0.733 & $\sim$ BMIS & 0.380 & 0.357 \\
SCN & 0.699 & 0.701 & $\sim$ SCN & 0.391 & 0.381 \\
STO & 0.745 & 0.705 & $\sim$ STO & 0.346 & 0.357 \\
CE & 0.732 & 0.742 & $\sim$ CE & 0.343 & 0.330 \\
CO & 0.639 & 0.703 & $\sim \mathrm{CO}$ & 0.455 & 0.407 \\
\hline
\end{tabular}


Next, the sufficiency analysis was carried out. A condition is sufficient when the outcome always occurs in presence of the condition [116]. To perform the analysis, a truth table was developed representing all possible combinations of causal conditions that lead to the outcome [41]. We refined the truth table through a logical minimization process based on frequency and consistency [37]. The frequency threshold was established at two, thereby forcing a minimum of two cases to be required for a solution [118]. The consistency cut-off (i.e., the minimum degree to which cases should correspond to the set-theoretic relationships expressed in a solution) was established at 0.80 [117]. As a result of the logical minimization of the truth table, three different solutions are obtained (conservative, intermediate and most parsimonious). We focused on the intermediate and parsimonious solutions as proposed by Fiss [84], also following his graphical representation.

Table 5 presents the six configurations obtained that lead to BMI in established SMEs. Black circles indicate the presence of a condition, and white circles indicate its absence. Large circles indicate that conditions are part of both parsimonious and intermediate solutions (core conditions), while small ones are only part of the intermediate solution (peripheral conditions). Blank spaces indicate that a condition is not relevant for the configuration. Thus, core conditions are those in which evidence indicates that the relationship with the outcome is strong, whereas for peripheral conditions the evidence shows that the link with the outcome is weaker [84]. Consequently, in a configuration, core conditions are commonly surrounded by peripheral conditions which highlight core conditions' main features [119]. As for core conditions, four recipes (1-4) empirically support the relevance of the conceptualizing and experimenting BMIC. Furthermore, according to solutions 5 and 6, SMEs achieved BMI in the absence of the collaborating BMIC and the presence of the sensing customer needs BMIC. In addition, sensing technological options is a peripheral condition in all six configurations, enhancing the central features of the aforementioned core conditions.

Table 5. FsQCA: Configurations for BMI in established SMEs.

\begin{tabular}{ccccccc}
\hline Configurations & \multicolumn{7}{c}{ Solutions } \\
\cline { 2 - 7 } & $\mathbf{1}$ & $\mathbf{2}$ & $\mathbf{3}$ & $\mathbf{4}$ & $\mathbf{5}$ & $\mathbf{6}$ \\
\hline Managerial orientation & $\bullet$ & 0 & $\bullet$ & $\bullet$ & $\bigcirc$ & $\bullet$ \\
Innovative culture & $\bullet$ & $\bullet$ & & $\bullet$ & $\bullet$ & $\bullet$ \\
Sensing customer needs & $\bullet$ & $\bullet$ & $\bullet$ & & $\bullet$ & $\bullet$ \\
Sensing technological options & $\bullet$ & $\bullet$ & $\bullet$ & $\bullet$ & $\bullet$ & $\bullet$ \\
Conceptualizing and experimenting & $\bullet$ & $\bullet$ & $\bullet$ & $\bullet$ & $\bigcirc$ & $\bigcirc$ \\
Collaborating & $\bullet$ & & $\bullet$ & $\bullet$ & $\bigcirc$ & $\bigcirc$ \\
BMI strategy & & $\bullet$ & $\bullet$ & $\bullet$ & $\bigcirc$ & $\bullet$ \\
Consistency & 0.989 & 0.989 & 0.903 & 0.891 & 0.808 & 0.974 \\
Raw coverage & 0.140 & 0.136 & 0.228 & 0.184 & 0.057 & 0.087 \\
Unique coverage & 0.017 & 0.025 & 0.073 & 0.030 & 0.014 & 0.045 \\
Overall solution consistency & 0.913 & & & & &
\end{tabular}

Note: Black circles indicate the presence of a condition, and white circles indicate its absence. Large circles indicate core conditions; small ones, peripheral conditions. Blank spaces indicate that a condition is not relevant for the configuration.

Overall solution consistency is 0.91 , and overall solution coverage is 0.43 , exceeding the recommended thresholds (consistency $>0.75$; coverage $>25$ ) for informative models [88]. Raw coverage refers to the portion of outcome is covered by each path, while unique coverage indicates the portion of outcome that is covered only by a specific path [116]. As for the paths identified, solutions 3 and 4 have the highest raw coverage values, followed by solutions 1 and 2 . Solution 3 indicates that the SMEs under study implemented BMI due to a long-term managerial orientation and the development of the five BMICs. As for solution 4, long-term managerial orientation and innovative culture that deployed four capabilities (i.e., sensing technological options, conceptualizing and experimenting, collaborating and BMI strategy) led to BMI in the studied SMEs. For solutions 3 and 4, consistencies 
of 0.9 and 0.89 , respectively, indicate that both are strongly supported by the gathered empirical evidence. Solution 1 shows that SMEs without long-term managerial orientation but with innovative culture and capabilities for sensing customer needs, sensing technological needs, conceptualizing and experimenting and collaborating SMEs can achieve BMI. In the case of SMEs following solution 2, with the absence of long-term managerial orientation, the presence of innovative culture and of the BMICs sensing customer needs, sensing technological needs, conceptualizing and experimenting and BMI strategy, also can lead to BMI. These findings are discussed in the next section.

\section{Discussion and Implications}

In the face of market dynamism that SMEs need to confront, BMI is a key factor in their competitiveness. Thus, BMI is a major challenge that needs to be addressed by SME managers, who tend to lack awareness of what BMI is and how they can develop it $[1,120]$. The number of publications actively addressing theoretical and quantitative research approaches to BMI is increasing [9,42]. In response, this research provides, from a qualitative comparative analysis perspective (i.e., fsQCA), new insights into the understanding of BMI in SMEs, empirically identifying different possible configurations for the management approach and BMICs involved in established SMEs.

In the next two subsections, we will further address the role of open innovation in BMI, as well as the configurational implications for stablished SMEs when approaching BMI.

\subsection{Discussion: Business Model Innovation and Open Innovation}

Although there are a variety of open innovation activities, both customer knowledge [121] and collaboration with customers [122] stand as cornerstones in the open innovation process, two factors that along with a strong managerial system and the activities of conceptualizing and experimenting, support BMI in SMEs.

Our findings suggest that customers are one of the most important sources of knowledge for BMI, and that this knowledge is obtained through the collaboration with customers in conceptualizing and experimenting, or through sensing customer needs.

Open innovation literature regarding SMEs stresses the fact that SMEs prefer to collaborate with customers in the first place [123], as corroborated with our fsQCA results (see Table 5). Our findings suggest that collaboration with customers need to be present when conceptualizing and experimenting are present as core conditions.

Furthermore, when collaborating, and conceptualizing and experimenting are absent, sensing customer needs is presented as a core condition. This open innovation activity [121] is a key capability for BMI, suggesting that SMEs incorporate open innovation for market reasons. This key capability is aimed to assure close cooperation between firm and customers (flow of knowledge from customers), in order to innovate. Therefore, sensing customer needs help SMEs to get advantage of this outside-in activity, moving established SMEs from a closed to an open innovation process [124].

Testing innovations with customers and sensing customer needs are core activities that help SMEs move from a closed to an open innovation process, while also being key capabilities for BMI. Therefore, a close interaction between customers and SMEs is needed to develop open innovation and BMI in established SMEs. In this context, BMI should be understood as the expected result (what an SME aims to achieve), while the open innovation activities (customer sensing and collaboration with customers) are key for this innovation process.

\subsection{Implications}

Regarding the configurational implications of our research, this study proposes that SMEs can achieve BMI through different, equally effective, combinations of managerial orientation, innovation culture and BMI capabilities (sensing customer needs, sensing technological options, conceptualizing and experimenting, collaborating and developing a BMI strategy). The results explored through fsQCA 
indicate that the combination of the five BMICs together with a long-term managerial orientation accounted for $23 \%$ of the achievement of BMI in SMEs (see solution 3 in Table 5).

Analyzing these results in detail, by comparing core and peripheral conditions, we detected that conceptualizing and experimenting was a core condition in four of the six recipes (see Table 5). Our findings add to previous research focused on measuring the extent of resources for experimentation [3], while offering a wider view of the conceptualizing and experimenting capability. Based on the above, we argue that SMEs should develop this capability of conceptualizing and experimenting in order to generate new ideas and experiment with new ways of creating and capturing value.

Results concerning technological capabilities (i.e., the sensing technological options BMIC), revealed that it is a peripheral condition in all six configurations. Thus, from an SME perspective, being up to date with new technological developments and opportunities seems to be a factor that enhances the central features of the core conditions conceptualizing and experimenting and sensing customer needs. We believe that this could be due to the increasing impact that digital transformation may be having on BMI [68]. Furthermore, these results reinforce the fact that technological innovation alone does not generate value unless it is exploited through BMI that creates value for both customers and the firm $[7,69]$.

Our results also suggest that the role of each one of the BMICs in the identified six configurations could derive from an iterative and multi-stage process view of BMI, where each stage represents different objectives and challenges [12]. Thus, SMEs in an initial stage of the BMI process might be strongly oriented to understanding customers and identifying unmet needs, paying less attention to conceptualizing and experimenting or collaborating, as these are capabilities associated with more advanced stages [12].

Finally, configurations also address a question that might have taken relevance for post-Covid-19 management agenda. Increasing uncertainty may reduce the capability of SMEs to develop long-term managerial orientation, but as suggested by the configurations with absence of long-term managerial orientation (Table 5), focusing on capabilities regarding conceptualization and experimentation, or sensing customer needs could be a successful recipe for BMI in a post-Covid-19 future.

\section{Conclusions, Limitations and Further Research}

This research empirically contributes to the BMI field, providing insights into how SMEs can stimulate BMI. Results point to two substantive conclusions. First, long-term managerial orientation is a key factor for the development of BMI in SMEs. Second, five BMI capabilities (sensing customer needs, sensing technological options, conceptualizing and experimenting, collaborating and BMI strategy) support, in combination with the management approach, the development of BMI in established SMEs. Furthermore, among the five BMICs analyzed we can conclude that conceptualizing and experimenting and sensing customer needs are key capabilities for BMI in SMEs, while the sensing technological options capability enhances these other two capabilities. Therefore, managers in SMEs need both to actively consider their management approach to BMI and to develop the needed dynamic capabilities in their organizations to implement BMI. Moreover, our research also underlines the idea that open innovation (open flows of knowledge regarding market needs and the potential of technologies, as well as collaboration with customers) are specific preconditions of business model innovation, and therefore are a proved starting point for new or improved business models [125].

This research also advances the knowledge of BMI in various ways. Firstly, we explored BMI through the lens of SMEs, following a configurational approach based on the use of fsQCA, while adding new insights to existing literature that is based mostly on large firms and qualitative studies $[1,3,120]$. Secondly, we developed a framework capturing the complexity of BMI in SMEs, integrating various drivers that, to date, have been underexplored, such as the roles of the SME's management approach (i.e., long-term managerial orientation and innovative culture) and BMICs in an integrated way. Additionally, through the development of the measurement instrument and the research framework we conceptually and empirically validated new scales for conceptualization and experimentation 
capabilities and also for BMI. We think that these scales are useful measurement instruments, providing a closer approach to the language used by SMEs $[1,120]$.

As for the managerial implications of this study, our research findings also provide some practical contributions for practitioners and SME managers, as well as for post-Covid-19 management. Beyond the uncertainty and complexity SMEs face in embracing BMI, research results suggest that SMEs should deploy a set of BMICs, promoting practices and routines focused on sensing customer needs, sensing technological options, conceptualizing and experimenting, collaborating and enacting a BMI strategy. These steps may facilitate the exploration and exploitation of opportunities and the development of BMI. At the same time, SMEs should have an active management approach based on a long-term managerial orientation and innovative culture that will foster BMI. Additionally, based on the six configurations proposed, we suggest that managers start developing the BMICs sensing customer needs and conceptualizing and experimenting as a first step when starting their BMI journey.

In this study, some limitations arise from the nature of the work. One is related to the use of a self-reported survey. Although several studies affirm that there is little difference between subjective and objective measures [122], further research based on objective data would be desirable. Another limitation is related to the small sample of SMEs and the regional scope of this exploratory study, which suggest that readers should interpret the results with caution when extending them to other geographical and innovation system contexts.

Future research activities could focus on investigating the causal relations among the variables in this study. Additionally, and bearing in mind that the present research focuses on some internal SME features, such as managerial orientation and innovative culture, further research could explore the BMI phenomenon in established SMEs by investigating new drivers. Moreover, fsQCA findings lead us to believe that SMEs could develop certain capabilities before others depending on their BMI maturity stage, and therefore we suggest that future research activities could adopt a maturity model approach. Future research on the collaborating capability, from an inbound and outbound open innovation perspective, could also help with this aim.

Finally, further research should be conducted to analyze whether our findings are industry specific, size specific or geographically specific, using larger samples and thus moving from exploratory to confirmatory research.

Author Contributions: Conceptualization, D.I., J.I.I., A.Z.B., J.G., Methodology, D.I., J.I.I., Data Analysis, D.I., J.I.I., Validation, D.I., J.I.I., A.Z.B., J.G, Writing-Original Draft Preparation, D.I., J.I.I., Writing-Review \& Editing, A.Z.B., J.G. All authors have read and agreed to the published version of the manuscript.

Funding: This research received no external funding.

Acknowledgments: The authors gratefully acknowledge participating SME managers for their helpful collaboration providing the data for this paper, as well as the Department of Economic Promotion, Tourism and Rural Environment of the Regional Council of Gipuzkoa for providing access to the databases. Additionally, we would like to thank the work of three anonymous reviewers for their contribution to improve this manuscript.

Conflicts of Interest: The authors declare no conflict of interest 


\section{Appendix A}

Table A1. Questionnaire: Antecedents.

\begin{tabular}{|c|c|c|}
\hline First-Order Constructs: Reflective Measurement Construct/Item & Loadings & $t$-Value \\
\hline \multicolumn{3}{|l|}{ Managerial Orientation $(\alpha=0.812 ; \mathrm{CR}=0.886 ; \mathrm{AVE}=0.724)$} \\
\hline $\begin{array}{l}\text { In the last } 3 \text { years, my strategic priorities in management have been oriented towards cost reduction } \\
\text { rather than investment (in R\&D, capital, etc.). [R] }\end{array}$ & 0.718 & 3.586 \\
\hline $\begin{array}{l}\text { In the last } 3 \text { years, my strategic priorities in management have focused on the short term rather than the } \\
\text { long term. [R] }\end{array}$ & 0.936 & 7.489 \\
\hline $\begin{array}{l}\text { In the last } 3 \text { years, my strategic priorities in management have focused on low-risk projects rather than } \\
\text { projects with greater potential but that entailed higher risks. [R] }\end{array}$ & 0.884 & 6.637 \\
\hline \multicolumn{3}{|l|}{ Organizational Culture $(\alpha=0.933 ; \mathrm{CR}=0.948 ; \mathrm{AVE}=0.786)$} \\
\hline We promote creativity and innovation. & 0.889 & 32.985 \\
\hline People are encouraged to experiment with new ways of doing their job. & 0.917 & 36.259 \\
\hline $\begin{array}{l}\text { We take advantage of people's knowledge and initiatives (collecting suggestions, encouraging them to } \\
\text { propose ideas or creating teams for the development of innovations). }\end{array}$ & 0.882 & 31.652 \\
\hline We promote open communication and interdepartmental exchange of information. & 0.881 & 17.542 \\
\hline We promote teamwork and interdepartmental cooperation. & 0.864 & 15.061 \\
\hline \multicolumn{3}{|l|}{ Sensing Customer Needs $(\alpha=0.707 ; \mathrm{CR}=0.833 ; \mathrm{AVE}=0.625)$} \\
\hline We systematically observe and evaluate the needs of our customers. & 0.853 & 14.550 \\
\hline We analyse the actual use of our products/services. & 0.776 & 8.242 \\
\hline Our organization is strong in distinguishing different groups of users and market segments. & 0.737 & 7.857 \\
\hline \multicolumn{3}{|l|}{ Sensing Technological Options $(\alpha=0.695 ; \mathrm{CR}=0.831 ; \mathrm{AVE}=0.624)$} \\
\hline We keep up to date with promising new products/services and technologies. & 0.761 & 5.544 \\
\hline $\begin{array}{l}\text { We use different sources of information to identify opportunities related to new products/services } \\
\text { and technologies. }\end{array}$ & 0.892 & 15.986 \\
\hline We follow which technologies our competitors use. & 0.705 & 7.207 \\
\hline \multicolumn{3}{|l|}{ Conceptualizing and Experimenting $(\alpha=0.893 ; \mathrm{CR}=0.918 ; \mathrm{AVE}=0.654)$} \\
\hline We frequently come up with new ideas for products, services, value propositions or business models. & 0.833 & 17.706 \\
\hline $\begin{array}{l}\text { We find it easy to convert ideas and concepts into detailed products, services, value propositions or } \\
\text { business models. }\end{array}$ & 0.824 & 16.978 \\
\hline New concepts are tested through prototypes and pilot tests before their final development. & 0.640 & 6.433 \\
\hline $\begin{array}{l}\text { We regularly experiment with new ways of both creating value for our customers and capturing value } \\
\text { from our innovations. }\end{array}$ & 0.860 & 28.496 \\
\hline $\begin{array}{l}\text { We combine technological, market, and business model knowledge in the idea generation and/or } \\
\text { experimentation processes. }\end{array}$ & 0.881 & 33.118 \\
\hline $\begin{array}{l}\text { When ideating new concepts, we analyse each of the elements of our business model (value } \\
\text { proposition, target customers, relationships and channels, activities and resources, cost and revenue } \\
\text { streams and key partnerships). }\end{array}$ & 0.791 & 16.814 \\
\hline \multicolumn{3}{|l|}{ Collaborating $(\alpha=0.781 ; \mathrm{CR}=0.861 ; \mathrm{AVE}=0.673)$} \\
\hline $\begin{array}{l}\text { We involve customers in our innovation processes (e.g., through active market research or developing } \\
\text { products/services based on their specifications). }\end{array}$ & 0.866 & 15.617 \\
\hline $\begin{array}{l}\text { We exchange knowledge with external partners (e.g., suppliers, universities, research centres, clusters, } \\
\text { public organizations or other organizations). }\end{array}$ & 0.809 & 8.347 \\
\hline We collaborate with external agents in the development of innovations. & 0.784 & 8.199 \\
\hline \multicolumn{3}{|l|}{ BMI Strategy $(\alpha=0.938 ; \mathrm{CR}=0.956 ; \mathrm{AVE}=0.844)$} \\
\hline We have a well-defined BMI strategy. & 0.917 & 32.528 \\
\hline BMI strategy is aligned with our firm's growth strategy. & 0.936 & 52.211 \\
\hline BMI strategy is clearly articulated as a means of generating growth throughout our organization. & 0.940 & 56.996 \\
\hline We have a well-defined action plan to execute and implement our BMI strategy. & 0.879 & 25.370 \\
\hline
\end{tabular}




\section{Appendix B}

Table A2. Questionnaire: BMI.

\begin{tabular}{|c|c|c|}
\hline High-Order Constructs: Reflective-Reflective MeasurementConstruct/Item & Loadings & $t$-Value \\
\hline \multicolumn{3}{|l|}{ Value Delivery $(\alpha=0.854 ; \mathrm{CR}=0.895 ; \mathrm{AVE}=0.632)$} \\
\hline In the last 3 years in our company we have met new customer needs previously unmet by the market. & 0.781 & 11.939 \\
\hline In the last 3 years in our company we have solved customer problems not solved by our competitors. & 0.811 & 15.383 \\
\hline In the last 3 years in our company we have introduced new forms of value for customers. & 0.862 & 25.363 \\
\hline $\begin{array}{l}\text { In the last } 3 \text { years in our company we have introduced new forms of value for other partners (suppliers } \\
\text { or distributors). }\end{array}$ & 0.756 & 13.255 \\
\hline $\begin{array}{l}\text { In the last } 3 \text { years in our company we have diversified into new markets, targeting completely new } \\
\text { customer types or new geographical environments }{ }^{a} \text {. }\end{array}$ & - & - \\
\hline In the last 3 years in our company we have expanded our activity to new customer segments. & 0.760 & 11.741 \\
\hline \multicolumn{3}{|l|}{ Value Creation $(\alpha=0.869 ; \mathrm{CR}=0.911 ; \mathrm{AVE}=0.719)$} \\
\hline $\begin{array}{l}\text { In the last } 3 \text { years in our company we have significantly modified the set of key activities of our } \\
\text { business through the acquisition or elimination of certain activities or their internal and/or external } \\
\text { reorganization, allowing us to be more efficient and improve our response. }\end{array}$ & 0.824 & 16.902 \\
\hline $\begin{array}{l}\text { In the last } 3 \text { years in our company we have established new collaborations with third parties that have } \\
\text { allowed us to optimize and improve our value proposition and/or business model. }\end{array}$ & 0.894 & 37.375 \\
\hline $\begin{array}{l}\text { In the last } 3 \text { years in our company we have integrated clients, suppliers, distributors and other agents in } \\
\text { innovative ways in relation to the delivery of products and services. }\end{array}$ & 0.827 & 12.878 \\
\hline $\begin{array}{l}\text { In the last } 3 \text { years in our company we have re-configured our value chain, allowing us to be more } \\
\text { efficient and to respond better to all interested parties. }\end{array}$ & 0.846 & 14.588 \\
\hline \multicolumn{3}{|l|}{ Value Capture $(\alpha=0.803 ; \mathrm{CR}=0.871 ; \mathrm{AVE}=0.629)$} \\
\hline In the last 3 years in our company we have introduced new ways to reduce costs. & 0.722 & 7.056 \\
\hline In the last 3 years in our company we have introduced new pricing mechanisms. & 0.731 & 7.173 \\
\hline In the last 3 years in our company we have introduced new ways to be profitable. & 0.896 & 21.815 \\
\hline In the last 3 years in our company we have introduced new revenue streams. & 0.811 & 13.547 \\
\hline \multicolumn{3}{|l|}{ BMI $(\alpha=0.810 ; \mathrm{CR}=0.887 ; \mathrm{AVE}=0.725)$} \\
\hline Value Delivery (BMI-DEL) & 0.773 & 9.403 \\
\hline Value Creation (BMI-CRE) & 0.899 & 37.319 \\
\hline Value Capture (BMI-CAP) & 0.877 & 24.213 \\
\hline
\end{tabular}

\section{References}

1. Pucihar, A.; Lenart, G.; Borštnar, M.K.; Vidmar, D.; Marolt, M. Drivers and outcomes of business model innovation-micro, small and medium-sized enterprises perspective. Sustainability 2019, 11, 344. [CrossRef]

2. Hock-Doepgen, M.; Clauss, T.; Kraus, S.; Cheng, C.F. Knowledge Management Capabilities and Organizational Risk-Taking for Business Model Innovation in SMEs. J. Bus. Res. 2020. Available online: http://dro.dur.ac.uk/ 30141/ (accessed on 8 July 2020). [CrossRef]

3. Bouwman, H.; Nikou, S.; De Reuver, M. Digitalization, business models, and SMEs: How do business model innovation practices improve performance of digitalizing SMEs? Telecommun. Policy 2019, 43, 101828. [CrossRef]

4. Teece, D.J. Business models, business strategy and innovation. Long Range Plan. 2010, 43, 172-194. [CrossRef]

5. Foss Nicolai, J.; Saebi, T. Business models and business model innovation: Between wicked and paradigmatic problems. Long Range Plan. 2018, 51, 9-21. [CrossRef]

6. Kranich, A.; Wald, P. Does model consistency in business model innovation matter? A contingency-based approach. Creat. Innov. Manag. 2018, 27, 209-220. [CrossRef]

7. Chesbrough, H.; Rosenbloom, R.S. The role of the business model in capturing value from innovation: Evidence from Xerox Corporation's technology spin-off companies. Ind. Corp. Chang. 2002, 11, 529-555. [CrossRef]

8. Amit, R.; Zott, C. Creating Value through Business Model Innovation. MIT Sloan Manag. Rev. 2012, 53, 41-49.

9. Foss, N.J.; Saebi, T. Fifteen Years of Research on Business Model Innovation. J. Manag. 2017, 9, 34-57. [CrossRef] 
10. Schneider, S.; Spieth, P. Business model innovation: Towards an integrated future research agenda. Int. J. Innov. Manag. 2013, 17, 1-34. [CrossRef]

11. Ghezzi, A.; Cavallo, A. Agile Business Model Innovation in Digital Entrepreneurship: Lean Startup Approaches. J. Bus. Res. 2020, 110, 519-537. [CrossRef]

12. Frankenberger, K.; Weiblen, T.; Csik, M.; Gassmann, O. The 4I-framework of business model innovation: A structured view on process phases and challenges. Int. J. Prod. Dev. 2013, 18, 249-273. [CrossRef]

13. Wirtz, B.W.; Daiser, P. Business Model Innovation: An Integrative Conceptual Framework. J. Bus. Models 2017, 5, 14.

14. Mezger, F. Toward a capability-based conceptualization of business model innovation: Insights from an explorative study. R D Manag. 2014, 44, 429-449. [CrossRef]

15. Teece, D.J. Business models and dynamic capabilities. Long Range Plan. 2018, 51, 40-49. [CrossRef]

16. Sosna, M.; Trevinyo-Rodríguez, R.N.; Velamuri, S.R. Business model innovation through trial-and-error learning: The naturhouse case. Long Range Plan. 2010, 43, 383-407. [CrossRef]

17. Chesbrough, H. Business model innovation: Opportunities and barriers. Long Range Plan. 2010, 43, 354-363. [CrossRef]

18. Bosco, D.; Roberto, B.C.; Mazzucchelli, A. Fostering entrepreneurship: An innovative business model to link innovation and new venture creation. Rev. Manag. Sci. 2019, 13, 561-574. [CrossRef]

19. Berends, H.; Jelinek, M.; Reymen, I.; Stultiëns, R. Product innovation processes in small firms: Combining entrepreneurial effectuation and managerial causation. J. Prod. Innov. Manag. 2014, 31, 616-635. [CrossRef]

20. Arbussa, A.; Bikfalvi, A.; Marquès, P. Strategic agility-driven business model renewal: The case of an SME. Manag. Decis. 2017, 55, 271-293. [CrossRef]

21. Snihur, Y.; Wiklund, J. Searching for innovation: Product, process, and business model innovations and search behavior in established firms. Long Range Plan. 2019, 52, 305-325. [CrossRef]

22. Damanpour, F. An integration of research findings of effects of firm size and market competition on product and process innovations. Br. J. Manag. 2010, 21, 996-1010. [CrossRef]

23. Belenzon, S.; Anastasiya, S.; Zarutskie, R. CEO's age and the performance of closely held firms. Strateg. Manag. J. 2019, 40, 917-944. [CrossRef]

24. García-Morales, V.J.; Lloréns-Montes, F.J.; Verdú-Jover, A.J. Influence of personal mastery on organizational performance through organizational learning and innovation in large firms and SMEs. Technovation 2007, 27, 547-568. [CrossRef]

25. Gherardini, F.; Renzi, C.; Leali, F. A systematic user-centred framework for engineering product design in small- and medium-sized enterprises (SMEs). Int. J. Adv. Manuf. Technol. 2017, 91, 1723-1746. [CrossRef]

26. Nicholas, J.; Ledwith, A.; Perks, H. New product development best practice in SME and large organisations: Theory vs practice. Eur. J. Innov. Manag. 2011, 14, 227-251. [CrossRef]

27. Osiyevskyy, J.O.; Oleksiy, D.O.; Dewald, J. Inducements, Impediments, and Immediacy: Exploring the Cognitive Drivers of Small Business Managers' Intentions to Adopt Business Model Change. J. Small Bus. Manag. 2015, 53, 1011-1032. [CrossRef]

28. Achtenhagen, L.; Leif, M.; Naldi, L. Dynamics of business models-strategizing, critical capabilities and activities for sustained value creation. Long Range Plan. 2013, 46, 427-442. [CrossRef]

29. Anwar, M. Business model innovation and SMEs performance-Does competitive advantage mediate? Int. J. Innov. Manag. 2018, 22, 1850057. [CrossRef]

30. Kraus, S.; Ribeiro-Soriano, D.; Schüssler, M. Fuzzy-set qualitative comparative analysis (fsQCA) in entrepreneurship and innovation research-The rise of a method. Int. Entrep. Manag. J. 2018, 14, 15-33. [CrossRef]

31. Harms, R.; Kraus, S.; Schwarz, E. The suitability of the configuration approach in entrepreneurship research. Entrep. Reg. Dev. 2009, 21, 25-49. [CrossRef]

32. Ricciardi, F.; Zardini, A.; Rossignoli, C. Organizational dynamism and adaptive business model innovation: The triple paradox configuration. J. Bus. Res. 2016, 69, 5487-5493. [CrossRef]

33. To Chester, K.M.; Au Joe, S.C.; Kan, C.W. Uncovering business model innovation contexts: A comparative analysis by fsQCA methods. J. Bus. Res. 2019, 101, 783-796. [CrossRef]

34. Liao, S.; Liu, Z.; Ma, C. Direct and configurational paths of open innovation and organisational agility to business model innovation in SMEs. Technol. Anal. Strateg. Manag. 2019, 31, 1213-1228. [CrossRef] 
35. Rumble, R.; Mangematin, V. Business Model Implementation: The Antecedents of Multi-Sidedness. Business Models Model. 2015, 33, 97-131. [CrossRef]

36. Massa, L.; Tucci, C.L. Business Model Innovation. In The Oxford Handbook of Innovation Management; Oxford University Press: Oxford, UK, 2013. [CrossRef]

37. Ragin, C. Redisigning Social Inquiry: Fuzzy Sets and Beyond; University of Chicago Press: Chicago, IL, USA, 2008; ISBN 9780226702735.

38. Cragun, D.; Pal, T.; Vadaparampil, S.T.; Baldwin, J.; Hampel, H.; DeBate, R.D. Qualitative Comparative Analysis: A Hybrid Method for Identifying Factors Associated with Program Effectiveness. J. Mix. Methods Res. 2016, 10, 251-272. [CrossRef] [PubMed]

39. De Block, D.; Vis, B. Addressing the Challenges Related to Transforming Qualitative Into Quantitative Data in Qualitative Comparative Analysis. J. Mix. Methods Res. 2018, 13, 503-535. [CrossRef]

40. Misangyi, V.F.; Greckhamer, T.; Furnari, S.; Fiss, P.C.; Crilly, D.; Aguilera, R. Embracing Causal Complexity: The Emergence of a Neo-Configurational Perspective. J. Manag. 2017, 43, 255-282. [CrossRef]

41. Rihoux, B.; Ragin, C.C. Configurational Comparative Methods: Qualitative Comparative Analysis (QCA) and Related Techniques; Sage Publications: Los Angeles, CA, USA, 2008; ISBN 1452210314.

42. Andreini, D.; Bettinelli, C. Business Model. Innovation: From Systematic Literature Review to Future Research Directions; Springer International Publishing: New York, NY, US, 2017; ISBN 9783319533513.

43. Arend, R.J. The business model: Present and future-beyond a skeumorph. Strateg. Organ. 2013, 11, 390-402. [CrossRef]

44. Ritter, T.; Lettl, C. The wider implications of business-model research. Long Range Plan. 2018, 51, 1-8. [CrossRef]

45. Belussi, F.; Orsi, L.; Savarese, M. Mapping Business Model Research: A Document Bibliometric Analysis. Scand. J. Manag. 2019, 35, 101048. [CrossRef]

46. Taran, Y.; Chester Goduscheit, R.; Boer, H. Managing business model innovation risks-lessons for theory and practice. In Proceedings of the 16th International CINet Conference on Pursuing Innovation Leadership, Stockholm, Sweden, 13-15 September 2015; ISBN 9789077360187.

47. Spieth, P.; Schneckenberg, D.; Ricart, J.E. Business model innovation-state of the art and future challenges for the field. R D Manag. 2014, 44, 237-247. [CrossRef]

48. Quintane, E.; Mitch Casselman, R.; Sebastian Reiche, B.; Nylund, P.A. Innovation as a Knowledge-Based Outcome. J. Knowl. Manag. 2011, 15, 928-947. [CrossRef]

49. Demil, B.; Lecocq, X. Business model evolution: In search of dynamic consistency. Long Range Plan. 2010, 43, 227-246. [CrossRef]

50. Mitchell, D.W.; Coles, C.B. The ultimate competitive advantage of continuing business model innovation. J. Bus. Strategy 2003, 24, 15-21. [CrossRef]

51. Bouwman, H.; Nikou, S.; Molina-Castillo, F.J.; De Reuver, M. The impact of digitalization on business models. Digit. Policy Regul. Gov. 2018, 20, 105-124. [CrossRef]

52. Bucherer, E.; Eisert, U.; Gassman, O. Towards Systematic Business Model Innovation: Lessons from Product Innovation Management. Creat. Innov. Manag. 2012, 21, 183-198. [CrossRef]

53. Azari, M.J.; Madsen, T.K.; Moen, O. Antecedent and outcomes of innovation-based growth strategies for exporting SMEs. J. Small Bus. Enterp. Dev. 2017, 24, 733-752. [CrossRef]

54. Huang, H.; Lai, M.; Lin, L.; Chen, C.-T. Overcoming organizational inertia to strengthen business model innovation: An open innovation perspective. J. Organ. Chang. Manag. 2013, 26, 977-1002. [CrossRef]

55. O'Regan, N.; Ghobadian, A.; Gallear, D. In search of the drivers of high growth in manufacturing SMEs. Technovation 2006, 26, 30-41. [CrossRef]

56. Bessant, J.; Tidd, J. Managing Innovation: Integrating Technological, Market and Organizational Change; John Wiley \& Sons: Hoboken, NJ, USA, 2013.

57. Hock, M.; Clauss, T.; Schulz, E. The impact of organizational culture on a firm's capability to innovate the business model. $R$ D Manag. 2016, 46, 433-450. [CrossRef]

58. Aksoy, H. How do innovation culture, marketing innovation and product innovation affect the market performance of small and medium-sized enterprises (SMEs)? Technol. Soc. 2017, 51, 133-141. [CrossRef]

59. Lazonick, W. Profits without Prosperity. Harv. Bus. Sch. 2014, 92, 46-55. 
60. Bailey, J.; Berube, V.; Godsall, J.; Kehoe, C. Short-Termism: Insights from Business Leaders; CPPIB McKinsey Co., 2014. Available online: https://www.fcltglobal.org/wp-content/uploads/20140123-mck-quarterly-surveyresults-for-fclt-org_final.pdf (accessed on 8 July 2020).

61. Vicente, A.; Paloma, R.; Ferasso, M.; May, M.R. Dynamic capabilities development and business model innovation: Evidences from IT industry in an emerging country. Int. J. Bus. Innov. Res. 2018, 17, 226-248. [CrossRef]

62. Inigo, E.A.; Albareda, L.; Ritala, P. Business model innovation for sustainability: Exploring evolutionary and radical approaches through dynamic capabilities. Ind. Innov. 2017, 24, 515-542. [CrossRef]

63. Roaldsen, I. Dynamic capabilities as drivers of business model innovation-from the perspective of SMEs in mature industries. Int. J. Entrep. Innov. Manag. 2014, 18, 349-364. [CrossRef]

64. Janssen, M.J.; Castaldi, C.; Alexiev, A. Dynamic capabilities for service innovation: Conceptualization and measurement. $R$ D Manag. 2016, 46, 797-811. [CrossRef]

65. Janssen, M.J.; Den Hertog, P. Developing Service-Based Business Models: Which Innovation Capability for Which Innovation Dimension? In Service Innovation; Springer International Publishing: New York, NY, USA, 2016; Volume 6, pp. 97-128. ISBN 978-4-431-54921-5.

66. Kiani, M.N.; Ahmad, M.; Gillani, S.H.M. Service innovation capabilities as the precursor to business model innovation: A conditional process analysis. Asian J. Technol. Innov. 2019. [CrossRef]

67. Rachinger, M.; Rauter, R.; Müller, C.; Vorraber, W.; Schirgi, E. Digitalization and its influence on business model innovation. J. Manuf. Technol. Manag. 2019, 30, 1143-1160. [CrossRef]

68. Ibarra, D.; Ganzarain, J.; Igartua, J.I. Business model innovation through Industry 4.0: A review. Procedia Manuf. 2018, 22, 4-10. [CrossRef]

69. Zott, C.; Amit, R.; Massa, L. The business model: Recent developments and future research. J. Manag. 2011, 37, 1019-1042. [CrossRef]

70. Lindgren, P. Business Model Innovation Leadership: How Do SME's Strategically Lead Business Model Innovation? Int. J. Bus. Manag. 2012. [CrossRef]

71. Warner, K.S.R.; Wäger, M. Building dynamic capabilities for digital transformation: An ongoing process of strategic renewal. Long Range Plan. 2019, 52, 326-349. [CrossRef]

72. Mueller, J.M.; Buliga, O.; Voigt, K. Fortune favors the prepared: How SMEs approach business model innovations in Industry 4.0. Technol. Forecast. Soc. Chang. 2018, 132, 2-17. [CrossRef]

73. Yun, J.H.J.; Jung, W.Y.; Yang, J. Knowledge strategy and business model conditions for sustainable growth of SMEs. J. Sci. Technol. Policy Manag. 2015, 6, 246-262. [CrossRef]

74. Scuotto, V.; Del Giudice, M.; Carayannis, E.G. The effect of social networking sites and absorptive capacity on SMES' innovation performance. J. Technol. Transf. 2017, 42, 409-424. [CrossRef]

75. Brunswicker, S.; Vanhaverbeke, W. Open Innovation in Small and Medium-Sized Enterprises (SMEs): External Knowledge Sourcing Strategies and Internal Organizational Facilitators. J. Small Bus. Manag. 2015, 53, 1241-1263. [CrossRef]

76. Lindgardt, Z.; Reeves, M.; Stalk, G.; Deimler, M.S. Business Model Innovation: When the Game Gets Tough, Change the Game; The Boston Consulting Group: Boston, MA, USA, 2009.

77. Chesbrough, H.W. Why Companies Should Have Open Business Models. MIT Sloan Manag. Rev. 2007, 48, 22.

78. Markides, L.; Sosa, C. Pioneering and first mover advantages: The importance of business models. Long Range Plan. 2013, 46, 325-334. [CrossRef]

79. Forkmann, S.; Henneberg, S.C.; Witell, L.; Kindström, D. Driver Configurations for Successful Service Infusion. J. Serv. Res. 2017, 20, 275-291. [CrossRef]

80. Meyer, A.D.; Tsui, A.S.; Hinings, C.R. Configurational Approaches to Organizational Analysis. Acad. Manag. J. 1993. [CrossRef]

81. Teece, D.J.; Pisano, G.; Shuen, A. Dynamic capabilities and strategic management. Strateg. Manag. J. 1997, 18, 509-533. [CrossRef]

82. Weimann, V.; Gerken, M.; Hülsbeck, M. Business model innovation in family firms: Dynamic capabilities and the moderating role of socioemotional wealth. J. Bus. Econ. 2020. [CrossRef]

83. Schilke, O.; Hu, S.; Helfat, C.E. Quo vadis, dynamic capabilities? A content-analytic review of the current state of knowledge and recommendations for future research. Acad. Manag. Ann. 2018, 12, 390-439. [CrossRef]

84. Fiss, P.C. Building better causal theories: A fuzzy set approach to typologies in organization research. Acad. Manag. J. 2011, 54, 393-420. [CrossRef] 
85. Fiss, P.C. A set-theoretic approach to organizational configurations. Acad. Manag. Rev. 2007. [CrossRef]

86. Vis, B. The Comparative Advantages of fsQCA and Regression Analysis for Moderately Large-N Analyses. Sociol. Methods Res. 2012. [CrossRef]

87. Leischnig, A.; Henneberg, S.C.; Thornton, S.C. Net versus combinatory effects of firm and industry antecedents of sales growth. J. Bus. Res. 2016. [CrossRef]

88. Woodside, A.G. Moving beyond multiple regression analysis to algorithms: Calling for adoption of a paradigm shift from symmetric to asymmetric thinking in data analysis and crafting theory. J. Bus. Res. 2013. [CrossRef]

89. Hughes, M.; Cesinger, B.; Cheng, C.F.; Schuessler, F.; Kraus, S. A configurational analysis of network and knowledge variables explaining Born Globals' and late internationalizing SMEs' international performance. Ind. Mark. Manag. 2017, 80, 172-187. [CrossRef]

90. Rangus, K.; Slavec, A. The interplay of decentralization, employee involvement and absorptive capacity on firms' innovation and business performance. Technol. Forecast. Soc. Chang. 2017, 120, 195-203. [CrossRef]

91. Fink, A. How to Conduct Surveys: A Step-by-Step Guide, 6th ed.; SAGE Publications: Los Angeles, CA, USA, 2016; ISBN 978-1-4833-7848-0.

92. Sarstedt, M.; Christian, M.R.; Hair, J.F. Partial Least Squares Structural Equation Modeling (PL-SEM): A useful tool for family business researchers. J. Fam. Bus. Strategy 2014, 5, 105-115. [CrossRef]

93. EU Commission. Commission recommendation of 6 May 2003 concerning the definition of micro, small and medium-sized enterprises (notified under document number C(2003) 1422) (Text with EEA relevance). Off. J. Eur. Union 2003, 124, 36-41.

94. Mikalef, P.; Pateli, A. Information technology-enabled dynamic capabilities and their indirect effect on competitive performance: Findings from PLS-SEM and fsQCA. J. Bus. Res. 2017, 70, 1-16. [CrossRef]

95. Genc, E.; Dayan, M.; Genc, O.F. The impact of SME internationalization on innovation: The mediating role of market and entrepreneurial orientation. Ind. Mark. Manag. 2019. [CrossRef]

96. De Vrande, V.; De Jong, V.; Jeroen, P.J.; Vanhaverbeke, W.; De Rochemont, M. Open innovation in SMEs: Trends, motives and management challenges. Technovation 2009, 29, 423-437. [CrossRef]

97. Huurinainen, J. Innovation Benchmark Study: Analysis of Innovation Processes in Finnish Companies. Master's Thesis, Lappeenranta University of Technology, Helsinki, Finland, 2007.

98. Covin, J.G.; Slevin, D.P. Strategic Management of Small Firms in Hostile and Benign Environments. Strateg. Manag. J. 1989, 10, 75-87. [CrossRef]

99. Zott, C.; Amit, R. The fit between product market strategy and business model: Implications for firm performance. Strateg. Manag. J. 2008, 29, 1-26. [CrossRef]

100. Schrauder, S.; Kock, A.; Baccarella, C.V.; Voigt, K. Takin'Care of Business Models: The Impact of Business Model Evaluation on Front-End Success. J. Prod. Innov. Manag. 2018, 35, 410-426. [CrossRef]

101. Verhagen, M. Business Model Innovation in European SMEs: Thriving Configurations and Performance Implications. Master's Thesis, Delft University of Technology, Delft, The Netherlands, 2018. Available online: https://repository.tudelft.nl/islandora/object/uuid\%3A66aae41f-7b0a-455b-b8ab-bf64fa13beb9 (accessed on 8 July 2020).

102. Sarstedt, M.; Hair, J.F.; Cheah, J.H.; Michael, B.J.; Ringle, C.M. How to specify, estimate, and validate higher-order constructs in PLS-SEM. Australas. Mark. J. 2019, 27, 197-211. [CrossRef]

103. Ringle, C.M.; Wende, S.; Becker, J.-M. SmartPLS 3. Bönningstedt: SmartPLS. 2015. Available online: http://www.smartpls.com (accessed on 8 July 2020).

104. Clauss, T. Measuring business model innovation: Conceptualization, scale development, and proof of performance. $R$ D Manag. 2017, 47, 385-403. [CrossRef]

105. Henseler, J.; Dijkstra, T.K.; Sarstedt, M.; Ringle, C.M.; Diamantopoulos, A.; Straub, D.W.; Ketchen, D.J.; Hair, J.F.; Hult, G.T.M.; Calantone, R.J. Common Beliefs and Reality About PLS: Comments on Rönkkö and Evermann (2013). Organ. Res. Methods 2014, 17, 182-209. [CrossRef]

106. Netemeyer, R.G.; Boles, J.S.; McMurrian, R. Development and validation of work-family conflict and family-work conflict scales. J. Appl. Psychol. 1996, 81, 400-410. [CrossRef]

107. Hogarty, K.Y.; Hines Constance, V.K.; Jeffrey, D.; Perron, J.; Mumford, M.; Karen, R. The quality of factor solutions in exploratory factor analysis: The influence of sample size, communality, and overdetermination. Educ. Psychol. Meas. 2005, 65, 202-226. [CrossRef] 
108. Sun, R.; Rohay, J.; Sereika, M.; Susan, M.; Zheng, Y.; Yu, Y.; Burke, L.E. Psychometric Evaluation of the Barriers to Healthy Eating Scale: Results from Four Independent Weight Loss Studies. Obesity 2019, 27, 700-706. [CrossRef] [PubMed]

109. Bearden, W.; Hardesty, O.; David, M.; Rose, R.L. Consumer Self-Confidence: Refinements in Conceptualization and Measurement. J. Consum. Res. 2001, 28, 121-134. [CrossRef]

110. Nunnally, J.C. Phychometric Theory; Tata McGraw-hill education: Pennsylvania, NY, USA, 1978.

111. Bollen, K.; Lennox, R. Conventional Wisdom on Measurement: A Structural Equation Perspective. Psychol. Bull. 1991. [CrossRef]

112. Hair, J.; Risher, F.; Jeffrey, J.; Sarstedt, M.; Ringle, C.M. When to Use and How to Report the Results of PLS-SEM. Eur. Bus. Rev. 2019, 31, 2-24. [CrossRef]

113. Henseler, J.; Hubona, G.; Ray, P.A. Using PLS path modeling in new technology research: Updated guidelines. Ind. Manag. Data Syst. 2016, 116, 2-20. [CrossRef]

114. Fornell, C.; Larcker, D.F. Evaluating Structural Equation Models with Unobservable Variables and Measurement Error. J. Mark. Res. 1981. [CrossRef]

115. Kline, R.B. Principles and Practice of Structural Equation Modeling, 3rd ed.; Guilford Publications: New York, NY, USA, 2011; ISBN 978-1-60623-876-9.

116. Schneider, C.Q.; Wagemann, C. Set-theoretic Methods for the Social Science: A Guide to Qualitative Comparative Analysis; Cambridge University Press: Cambridge, UK, 2012; ISBN 9781107601130.

117. Duarte, P.; Pinho, J.C. A mixed methods UTAUT2-based approach to assess mobile health adoption. J. Bus. Res. 2019, 102, 140-150. [CrossRef]

118. Salam, M.A.; Ali, M.; Kan, S.; Anderson, K. Analyzing supply chain uncertainty to deliver sustainable operational performance: Symmetrical and asymmetrical modeling approaches. Sustainability 2017, 9, 2217. [CrossRef]

119. Leischnig, A.; Geigenmüller, A. When does alliance proactiveness matter to market performance? A comparative case analysis. Ind. Mark. Manag. 2018. [CrossRef]

120. Heikkilä, M.; Bouwman, H.; Pucihar, A.; Kljajić Borštnar, M.; Ravesteijn, P.; Seitz, J.; Bons, R. Business Model Innovation in European SMEs: Descriptive analysis of quantitative survey and case survey data. Digit. Transform. Meet. Chall. 2018, 543-560. [CrossRef]

121. Jokubauskienè, R.; Vaitkienè, R. Assumptions of Customer Knowledge Enablement in the Open Innovation Process. Econ. Bus. 2017, 31, 55-69. [CrossRef]

122. Kraus, S.; Rigtering, J.; Coen, P.; Hughes, M.; Hosman, V. Entrepreneurial orientation and the business performance of SMEs: A quantitative study from the Netherlands. Rev. Manag. Sci. 2012, 6, 161-182. [CrossRef]

123. Torchia, M.; Calabrò, A. Open Innovation in SMEs: A Systematic Literature Review. J. Enterprising Cult. 2019, 27, 201-228. [CrossRef]

124. Chiaroni, D.; Chiesa, V.; Frattini, F. Unravelling the process from Closed to Open Innovation: Evidence from mature, asset-intensive industries. $R$ D Manag. 2010, 40, 222-245. [CrossRef]

125. Yun, J.J.; Yang, J.; Park, K. Open Innovation to Business Model: New Perspective to connect between technology and market. Sci. Technol. Soc. 2016, 21, 324-348. [CrossRef]

(C) 2020 by the authors. Licensee MDPI, Basel, Switzerland. This article is an open access article distributed under the terms and conditions of the Creative Commons Attribution (CC BY) license (http://creativecommons.org/licenses/by/4.0/). 